\title{
Analysis on the seismic performance of improved design on FRC diagonally reinforced coupling beams
}

\author{
CHE Jialing ${ }^{1, a^{*}}$, LI Quanwei ${ }^{1, b}$, YANG Shujuan ${ }^{1, c}$, Han Guansheng ${ }^{1, d}$ \\ 1 School of Civil Engineering and Water Conservancy, Ningxia University, China \\ ache_jialing@126.com, b278501521@163.com, '2378325336@qq.com, d1554434259@qq.com
}

\begin{abstract}
Key words: coupling beam; small span-depth ratio; FRC; numerical simulation; improved design Abstract: Uniaxial tensile strain of FRC is 100-300 times of that of the ordinary concrete, with tensile strain hardening behavior. The experiment study showed that if FRC was used to replace ordinary concrete as the diagonal reinforcement small span-depth ratio coupling beam matrix, it can improve the ductility and energy dissipation capacity of small span-depth ratio beams, reduce the amount of steel. On the basis of experimental study, the FRC beam finite element model was established based on ABAQUS finite element software. Based on experimental study of FRC beams, by using unbonded technique, the improved reinforcement scheme of sleeve PVC casing in the length range of 1/4 beam height of FRC bearing capacity of longitudinal reinforcement near the wall was proposed, and by using the established numerical model, the superiority of the improved design scheme was discussed. The results showed that the improved design scheme had better bearing capacity, ductility and energy dissipation capacity compared with the original scheme.
\end{abstract}

\section{Introduction}

Coupled shear wall is a common structural form in the modern high-rise structure. According to the mechanical characteristics of the coupling shear wall, the transfer function of coupling beams between wall limbs can be used to resist the overturning moment caused by the base shear force, it is the first seismic fortification line for the coupled shear wall, its ductility performance and energy dissipation capacity have an important influence on the seismic performance of the whole structure. Due to the structural function and design requirements, the joint shear bending of the coupled wall structure is relatively large, and the small span-height ratio coupling beam that is prone to shear failure before the required ductility exist. In order to ensure the span-depth ratio coupling beam meet the requirements of the seismic performance of high ductility and good energy dissipation capacity, Paulay T. proposed adding reinforcement diagonal hidden cross column beam based on the traditional beam reinforcement, the experimental research and practice showed that hidden cross column reinforcement had better ductility and higher energy dissipation capacity, but its drawbacks were huge amount of steel, and construction difficulty ${ }^{[1]}$. Aiming at the small bar spacing, construction difficulty of cross hidden column reinforcement, scholars of various countries had put forward the diamond truss type ${ }^{[2,3]}$, 3-layer closed hoops ${ }^{[4]}$, composite inclined reinforcement ${ }^{[5]}$ and other reinforcement schemes.

Another research idea is, while adding diagonal reinforcement, the FRC was adopted to replace ordinary concrete beams as matrix material. And the study showed that when FRC was used in shear based component as matrix material, it can reduce the number of shear reinforcement, increase the shear strength, deformation capacity and energy dissipation capacity of members ${ }^{[6-9]}$. On the basis of the study of FRC, the studying team proposed FRC diagonally reinforced coupling beams, and the results shows that FRC diagonal reinforcement coupling beam is easy to construct 
and it's seismic performance is improved obviously ${ }^{[10,11]}$.

In order to further improve ductility and energy dissipation capacity of the small span-depth ratio coupling beam, on the basis of literature [10], this paper proposed a new reinforcement scheme of coupling beam, that is, using FRC to replace ordinary as coupling beam matrix of diagonal reinforcement.At the same time,put PVC casing in the longitudinal reinforcement near the height of $1 / 4$ beam, and dispose it with unbonded technique. Then, by using the ABAQUS software, to study the feasibility of the improved scheme.

\section{The establishment of numerical model}

Unit selection. In this paper, based on ABAQUS software, the numerical model of FRC beam was established, and in the finite element model, the simulation of steel bar can be separated and combined $^{[11]}$. Considering the advantages and disadvantages of two kinds of modeling methods, this paper selected the layered shell element and combined with the reinforcement separation model to simulate the joint wall structure. The S4R element was used to simulate the beam and beam end shear wall. Beam end shear wall uses rigid body ${ }^{[8]}$.

Numerical model validation. 3 FRC diagonal reinforcement small span-depth ratio coupling beam specimens in literature [10] were selected to verify the reliability of numerical model. Dimensions and related parameters of specimens were shown in Figure 1 and table 1. By using ABQUS, 3 FRC diagonally reinforced coupling beams with small span-depth ratio test numerical models were set, figure 2 was the comparison chart of beam test skeleton curve and numerical simulation skeleton curve, figure 3 was the failure pattern comparison between coupling beam test and numerical simulation. The results showed that the numerical simulation results were in good agreement with the experimental results, which can be used as the basis for further analysis.

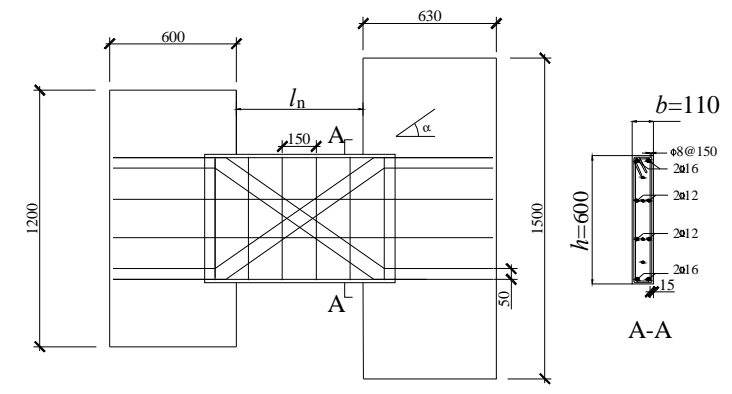

Fig.1 Sketch map of specimen size and reinforcement

Table 1 Basic parameters of specimens

\begin{tabular}{ccccc}
\hline No. & $\begin{array}{c}\text { span-depth } \\
\text { ratio }\end{array}$ & $\begin{array}{c}\text { Number of diagonal } \\
\text { reinforce-ment }\end{array}$ & $\begin{array}{c}\text { Angle of oblique } \\
\text { ribs[ degree] }\end{array}$ & $\begin{array}{c}f_{\text {cu }} / \\
{[\mathrm{MPa}]}\end{array}$ \\
\hline CB-3 & 1.00 & $2 \$ 10$ & 35 & 38.9 \\
CB-4 & 1.25 & $2 \$ 14$ & 30 & 45.9 \\
CB-5 & 1.5 & $2 \Phi 18$ & 26 & 60.0 \\
\hline
\end{tabular}

Note: $f_{\text {cu }}$ is the average compressive strength of concrete cube 


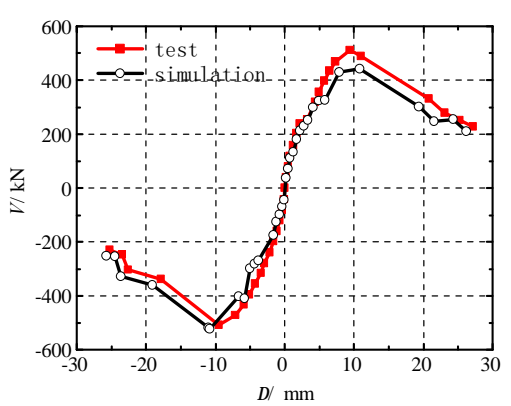

(a) $\mathrm{CB} 3$

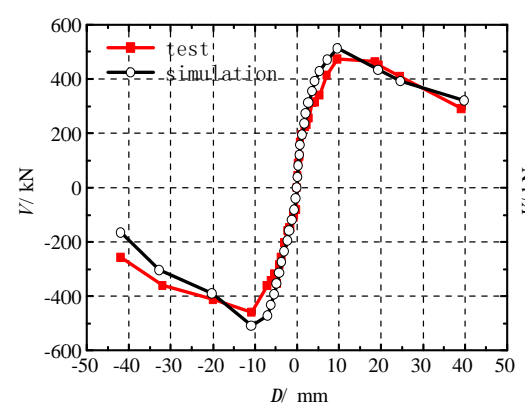

(b) CB4

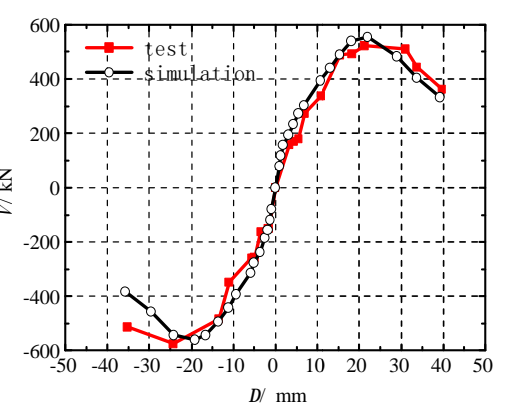

(c) CB5

Fig.2 Skeleton curve of coupling beam test and numerical Simulation

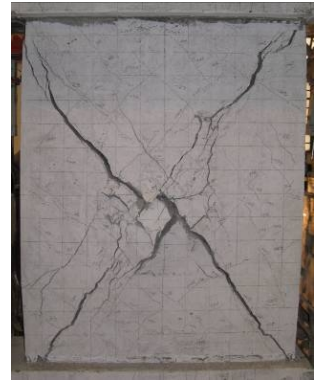

(a) test

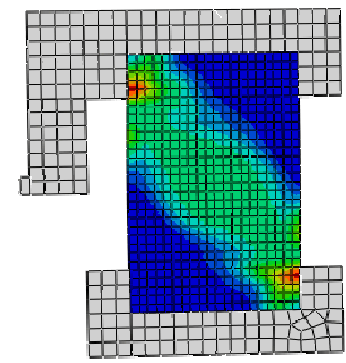

(b) finite element simulation

Fig.3 Failure pattern comparison of coupling beam

\section{Improvement scheme of FRC diagonally reinforced coupling beams with small span-depth ratio}

Based on the existing research, this paper proposed a local unbonded technology, that is, to put PVC casing in the longitudinal reinforcement near the height of $1 / 4$ beam. In order to compare stress performance between the new reinforcement scheme coupling beam and FRC beam, this paper used the finite element software ABAQUS to establish 3 finite element calculation models of partial unbonded FRC beam. Other parameters, respectively, were same with CB-3, CB-4, and CB-5 in the literature [9].

The load and displacement value of new reinforcement beam and 3 FRC coupling beams in literature [9] were shown in table 2. Among them, The yield load, according to the coupling beam load-displacement skeleton curve, was determined by the general yield moment method, namely: making a tangent over origin 0 contacting with $\mathrm{P}$ - curve, as shown in figure 4.

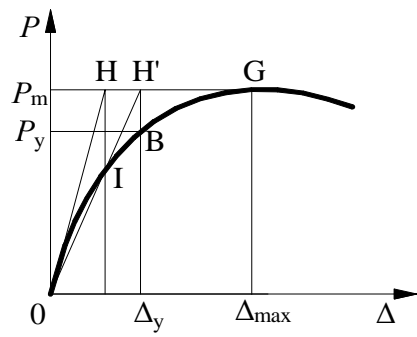

Fig.4 The general yield moment method is used to determine the yield

Ductility is defined as the deformation capacity with no significant strength or stiffness degradation after structure or the selected structure partially exceeding the elastic limit. Ductility is an important index to measure the seismic performance of structures, and the displacement ductility 
factor is often used to measure the ductility. The displacement ductility factor is the ratio of the limit displacement and the yield displacement. That is,

$$
\mu=\frac{\Delta_{\mathrm{u}}}{\Delta_{\mathrm{y}}}
$$

In the formula, $\mu$ is displacement ductility coefficient; $\Delta_{\mathrm{u}}$ is limit displacement; $\Delta_{\mathrm{y}}$ is yield displacement. Ultimate displacement $\Delta_{u}$ of coupling beam specimen is selected as the corresponding displacement when the bearing capacity of coupling beams decreased by $85 \%$.

Table 2 Comparison of numerical simulation results between the original scheme and the improved scheme

\begin{tabular}{|c|c|c|c|c|}
\hline \multicolumn{2}{|c|}{ No. } & Yield load $/ \mathrm{kN}$ & Ultimate load $/ \mathrm{kN}$ & $\begin{array}{l}\text { Ductility } \\
\text { coefficient }\end{array}$ \\
\hline \multirow{2}{*}{ CB3(R/FRC) } & $\begin{array}{c}\text { (Before } \\
\text { improvement) }\end{array}$ & 385 & 533 & 2.6 \\
\hline & $\begin{array}{l}(\mathrm{New} \\
\text { reinforcement })\end{array}$ & 431 & 634 & 3.4 \\
\hline \multirow{2}{*}{ CB4(R/FRC) } & $\begin{array}{c}\text { (Before } \\
\text { improvement) }\end{array}$ & 377 & 512 & 2.8 \\
\hline & $\begin{array}{l}(\mathrm{New} \\
\text { reinforcement })\end{array}$ & 426 & 620 & 3.7 \\
\hline \multirow{2}{*}{ CB5(R/FRC) } & $\begin{array}{c}\text { (Before } \\
\text { improvement) }\end{array}$ & 421 & 545 & 2.9 \\
\hline & $\begin{array}{l}(\mathrm{New} \\
\text { reinforcement) }\end{array}$ & 480 & 670 & 3.9 \\
\hline
\end{tabular}

The comparative analysis shows that the load-displacement curves of the two groups are almost coincident and proportionally increase in the initial stage of loading. The yield load and yield displacement in improved scheme 2 were lower than those before the improvement, but with the increasing of load, ultimate load and ductility coefficient of coupling beam was obviously improved. Among them, the limit load is increased by 1.12 times, and the ductility factor increased by 1.35 times. With the increase of the span-depth ratio, the degree of increase is gradually reduced with the increasing of load, the yield load of unbonded reinforced beams was lower than that of bonding time. But because of the better ductility, larger bearing capacity during no bond in the beam longitudinal reinforcement, the deformation and energy dissipation capacity were improved to a certain extent, which were also easy to realize coupling beam bending failure or shear failure requirements.

\section{Conclusions}

Based on the study of FRC coupling beam, this paper has set up finite element model of FRC coupling beam, An improved reinforcement scheme is proposed, in which the longitudinal reinforcement ribs of FRC coupling beams near the height of 1/4 beam, to put PVC casing. And the finite element software ABAQUS is used to simulate the numerical simulation, results show that: 
(1) The established numerical simulation method can better simulate the skeleton curve whose matrix is FRC coupling beam under low reversed cyclic loading, which can fully reflect the stress and deformation characteristics of FRC coupling beam under low reversed cyclic loading.

(2) When no bonding in the longitudinal reinforcement at the end of coupling beam, the ultimate bearing capacity of coupling beams is higher than that of longitudinal reinforcement bonding.

(3) Ductility and energy dissipation capacity of the improved scheme are good, which can be easy to realize beam bending failure or beam shear failure requirements.

(4) For coupling beam with small span-depth ratio, its final failure mode is shear failure, but, due to the use of local unbonded technology, it is beneficial to the development of bending crack at the end of the beam, and its carrying capacity, ductility and energy dissipation capacity are effectively improved.

\section{Acknowledgements}

This work was financially supported by the National Natural Science Foundation of China with No. 51408328,Dr. Research Launch of Ningxia university in China.

\section{References}

[1] R. Park,T. Paulay. Reinforced concrete structures[M]. New York: John Wiley \& Sons,1975.

[2] I.A. Tegos,G. GR. Penelis. Seismic Resistance of Short Columns and Coupling Beams Reinforced with Inclined Bars[J]. ACI Structural Journal,1988,85(1):82-88.

[3] Sun Zhanguo, Lin Zongfan, Dai Ruitong. Behavior of Coupling Beam of Shear Wall Reinforced with Inclined Rhomboidal Bars[J]. Journal of Building Structures, 1994,15(5):14-23. (in Chinese)

[4] Liang Xingwen, Li Fangyuan, Zhang Tao, et al. Experimental study on seismic behavior of new reinforcement scheme deep coupling beams[J]. Engineering Mechanics,2009,26(12): 119-126. (in Chinese)

[5] Fu Jianping,Pi Tianxiang, Wei Feng, et al. Experimental study on seismic behavior of small aspect ration coupling beams in RC structural walls proportioned with combined slanting reinforcements[J]. China Civil Engineering Journal,2011,44(02):57-64. (in Chinese)

[6] S. L. Billington,J. K. Yoon. Cyclic response of precast bridge columns with ductile fiber-reinforced concrete[J]. Journal of Bridge Engineering,ASCE,2004,9(4):353-363.

[7] V. C. Li,S. Wang,C. Wu . Tensile strain-hardening behavior of PVA-ECC[J]. ACI Material,2001,98(6):483-492.

[8]Che Jialing. Research on Seismic Performance and Design Method of FRC Diagonally Reinforced Coupling Beams and Coupled Shear Walls[D]. Xi'an:Xi'an University of Architecture and Technology,2013.

[9] Liang Xingwen,Che Jialing,Deng Mingke. Experimental research on seismic behavior of FRC diagonally reinforced coupling beams with the small ratio of span to depth[J]. Journal of Building Structures,2013,34(8):135-141. (in Chinese)

[10] Brad D. Weldon, Yahya C. Kurama. Analytical modeling and design validation of posttensioned precast concrete coupling beams for seismic regions[J] . Journal of Structural Engineering,2012,138(2):224-234.

[11] Che Jialing,Liang Xingwen,Dang Zheng, et al. Numerical simulations and design method of 
coupled wall system with FRC coupling beams[J]. Journal of Civil Architectural \& Environmental Engineering,2012,34(4):72-79. 